\title{
CCR6-CCL20 Axis in IBD: What Have We Learnt in the Last 20 Years?
}

\author{
Ranmali Ranasinghe $(\mathbb{D}$ and Rajaraman Eri *iD \\ School of Health Sciences, College of Health and Medicine, University of Tasmania, \\ Launceston 7248, Tasmania, Australia; ranmaliranasinghe301@gmail.com \\ * Correspondence: rderi@utas.edu.au
}

Received: 21 August 2018; Accepted: 12 October 2018; Published: 15 October 2018

\begin{abstract}
CC chemokine receptor 6 (CCR6) and its specific partner CC chemokine ligand 20 (CCL20) are known to play a pivotal role in intestinal inflammation. CCR6-associated inflammatory bowel disease (IBD) is already at the forefront of experimental inflammatory disease models, being the subject of numerous analytical studies. IBD is associated with two sub phenotypes, Crohn's disease (CD) and ulcerative colitis (UC). Both these disease entities produce potent immune dysregulation followed by intense tissue damage within the gut mucosal system, initiating symptoms that are severely debilitating. Multiple causative factors are said to be responsible for IBD, but direct immune dysfunction is kindled by overplay of innate and adaptive immune responses produced against the luminal contents through the weakened or leaky gut epithelial barrier. Once immune homeostasis is not achieved by endogenous protective mechanisms, the self-assertive adaptive immunity mobilizes its various $\mathrm{T}$ and $\mathrm{B}$ cell cohorts, initializing their immune mechanisms by deploying the immune cells towards the site of infection. CCR6 and its unique solitary ligand CCL20 are small protein molecules that are abundantly expressed by $\mathrm{T}$ and $\mathrm{B}$ lymphocytes and act as chemotactic immune-modulatory envoys that help in the deployment of the effector lymphocyte arm of the immune system and produce two directly opposing outcomes in IBD. This dichotomous immunity consists of either immune tolerance or inflammation which then develops into a chronic state, remaining unresponsive to inherent immunity or targeted clinical therapy. In this review, we have identified large numbers of experimental studies that have employed both mouse models and clinical subjects spanning a period of nearly two decades and we have clustered these into 13 different groups. This review will provide greater understanding of the CCR6-CCL20 axis in IBD and identify gaps in the literature that can be filled in the future.
\end{abstract}

Keywords: inflammatory bowel disease; CCR6; CCL20; T helper lymphocytes; regulatory T cells; dendritic cells; TH17/Treg balance

\section{Introduction}

\subsection{Inflammatory Bowel Disease (IBD)}

Inflammatory bowel disease (IBD) essentially consists of two diseases, Crohn's disease (CD) and ulcerative colitis $(\mathrm{UC})$ of the gastrointestinal tract, which have a poor prognosis and are unresponsive to most current treatment regimens. $\mathrm{CD}$ is a transmural, segmental disease that can affect any part of the alimentary canal, whereas UC is restricted to the colon and the rectum. IBD has a global presence, with the majority of cases being recorded from Europe, America and Australia. The average cost of managing the disease per annum in Australia alone is in the range of $\$ 250,000$. Although genetic predisposition plays a critical role with more than 200 susceptibility gene loci being already identified, all age groups from all walks of life are at risk of contracting IBD linked to a host of environmental 
determinants, diet and altered gut microbiome. Its excruciating symptoms are abdominal pain, bloody diarrhea, vomiting, nausea, urgency to evacuate, severe weakness and necrotic fibrosis which could recur intermittently between bouts of remission. If clinical therapy fails to produce responsiveness, surgical intervention becomes compulsory. IBD that is unresponsive to therapy may develop into colorectal carcinoma or other cancers in the gut [1-8].

\subsection{Chemokines-Chemokine Receptor 6 (CCR6) and CC—Chemokine Ligand 20 (CCL20)}

Chemokines are an exclusive group of small molecular cytokines which are chemoattractant by nature and direct leukocyte migration to inflamed tissue microenvironments within the gut mucosa during IBD. Chemokines comprise of receptors and their ligands, and the complimentary receptor-ligand pairs together actively mobilize the leukocytes during immune or inflammatory responses. There are four major divisions of chemokines namely $\mathrm{CC}, \mathrm{CXC}, \mathrm{XC}$ and $\mathrm{C}$, with the common feature being separated by cysteine motifs having disulfide bonds. One chemokine receptor may bind with several chemokine ligands or multiple receptors could partner with one chemokine ligand. Biochemically, chemokines are small proteins consisting of lower molecular weights around 8-14 kD. Biological activities of chemokines are numerous, which include embryogenesis, wound healing, development of vasculature, $\mathrm{T}$ lymphocyte development and differentiation, leukocyte homeostasis, B cell development and maturation [9-12].

CC motif chemokine receptor 6 (CCR6) is abundantly expressed by $\mathrm{T}$ and $\mathrm{B}$ memory lymphocytes, antigen-presenting cohorts (APC) including the dendritic cells, macrophages, the $\mathrm{CD}^{+} \mathrm{T}$ helper lymphocytes, innate lymphoid cells (ILC) and epithelial cells. It propels these cells towards its chemokine ligand 20 (CCL20) which is released in copious quantities by the gut epithelium in response to microbial stimulation. CCR6 has been identified in the thymus, appendix, fetal liver, small intestine, colon, spleen and lymph nodes. CCL20, also known as liver and activation-regulated chemokine (LARC), macrophage inflammatory protein-3 alpha (MIP-3 $\alpha$ ) and Exodus-1, is secreted by the endothelium, neurons and the gut epithelium. CCR6 is a member of the G protein-coupled receptor (GPCR) superfamily which, upon binding with CCL20, initiates the classical signaling pathway via the activation of heterotrimeric $\mathrm{G}$ proteins belonging to the $\mathrm{G} \alpha \mathrm{i}$ family. Its downstream signaling involves activation of calcium influx through the phosphatidylinositol 3-kinase (PI3K)/Akt, extracellular signal-regulated kinases (ERK1/2) phosphorylation which leads to actin polymerization by recruiting the arrestin proteins such as beta arrestin 1 and 2 to form a scaffold for the signaling molecules. Distinct clusters of serine/threonine (Ser/Thr) residues at the carboxyl terminal of CCR6 differentially regulate the biological functions of the receptor [13].

A vital aspect of the CCR6-CCL20 axis in IBD is that it maintains the Thelper lymphocyte 17 (TH17)/regulatory Treg balance during the initiation of immune tolerance, although inflammation arises as a direct result of the dysregulation of TH17-Treg paradigm. Naïve T helper lymphocytes upon antigen priming by APC develop into effectors consisting of T helper lymphocyte 1 (TH1), TH2, TH17 and regulatory Treg cell subsets in the lymphoid organs and migrate towards the inflammatory locations in the gut mucosa. Contrary to the earlier belief of TH1/TH2 dual immune activation pathways in IBD, TH17-Treg dysfunction has recently being implicated, although the immune-driven cues and inherent mechanisms remain obscure. TH17 cells are associated with an inflammatory phenotype whereas the regulatory Treg cells are linked to an anti-inflammatory suppressive (protective) role [9-12].

CCR6 expression on TH17 is induced by the pro-inflammatory cytokines interleukin (IL), IL-17A-F, IL-21, IL-22, IL-23, IL26, IL-1 $\beta$, IFN- $\gamma$, IL-6 and tumor necrosis factor-alpha (TNF- $\alpha$ ) along with the transcription factors retinoic-acid-receptor-related orphan nuclear receptor gamma $t(R O R \gamma t)$, signal transducer and activator of transcription 3 (STAT3) and nuclear factor kappa B (NF-KB). CCR6 expression on regulatory Treg cells is induced by transforming growth factor-beta (TGF- $\beta$ ) and IL-10 together with the nuclear receptor forkhead box P3 (FoxP3). Interestingly, experimental studies suggest that both TH17 and Treg cells can oscillate between both inflammatory and suppressive 
roles [9-12]. Additionally, CCR6-CCL20 may have pleiotropic immunological roles in a variety of inflammatory disorders involving the human organs: skin, liver, lung, kidney, brain, eye, joints, gonads and gut, as well as human sperm, human immunodeficiency virus (HIV) and cancer metastasis [9].

\subsection{Immunological Pathogenesis in IBD}

IBD is characterized by the secretion of pro-inflammatory cytokines, especially the IL-1 family. IL-1, which is said to originate from monocytes and macrophages, causes distinctive inflammation in UC patients and active IL-1 $\beta$ has been detected in their colonic mucosa. IL-18, evokes a TH1 response and was significantly elevated in the mucosal tissue of CD patients. Furthermore, IL-18 has been demonstrated to lower the levels of IL-10 released by T cells in the gut mucosa during acute CD. A TH2 response is elicited by IL-33 which is known to promote the protection of the intestinal epithelium by secreting excessive mucous and increased discharge of IL-5 and IL-13 expression. UC patients evidently demonstrated IL-33 expression and that of ST2, which is its receptor. Another pro-inflammatory cytokine, IL-6, is upregulated along with its soluble IL-6 receptor in both UC and CD patients. IL-6 is linked to the severity of pathogenesis in UC as well as inducing colorectal carcinoma in patients afflicted with UC. Tumor necrosis factor-alpha (TNF- $\alpha$ ) holds superiority over IL-1 $\beta$, IL-33 and IL- 6 in IBD because the levels of these three cytokines are upregulated by TNF- $\alpha$ which causes severe inflammation in the gut and is markedly raised in serum during episodes of both CD and UC. The expression of IL-10, the immunoregulatory cytokine, is controversial in IBD, as its levels remain the same or higher compared to the healthy controls. Yet serum IL-10 levels are elevated in CD patients and IL-10 gene expression is higher in mucosal T cells taken from UC subjects. IL-17 produces a strong inflammatory response in IBD through the activation of signal transducer and activator of transcription 3 (STAT3). It is well documented that the IL-17 messenger ribonucleic acid (mRNA) in the mucosa is increased during CD and UC whilst IL-17 inhibition is known to decrease mucosal inflammation. IL-17 is also known to recruit more T cells into the lamina propria (LP) during inflammation as well as to protect the human intestinal epithelium by strengthening tight junction formation. TH17 cells which release IL-17 and related cytokines are a major factor causing pathogenicity in IBD. Prolific infiltration of TH17 cells takes place in the inflamed gut mucosa during IBD. The differentiation of TH17 cells is influenced by the luminal microbiota, and experimental evidence has shown that it is reduced in germ-free mice or mice treated with antibiotics. The most recently developed concept describes the pivotal role of TH17 and Treg cell subsets in the progression of IBD. Treg cells play a key role in defining immune tolerance through mounting immune responses against the enteric commensal flora to maintain immune homeostasis. Poor Treg cell differentiation markedly increases IBD severity and susceptibility. The importance of Treg cells are further highlighted by (i) increased inflammation due to loss of IL-10, (ii) increased colitis due to impaired transforming growth factor-beta one (TGF- $\beta 1$ ) signal transduction, (iii) impaired Treg cell function due to mutations in CD25 and IL-10, and (iv) reduced inflammation in the gut of recombination activating gene 1 knock out (RAG1 KO) mice upon adoptive co-transfer of T cells and Treg cells. Therefore, it is immensely important to be able to identify the immune ingredients that tilt this precarious immune imbalance of TH17 versus Treg cells towards a cure pathway [14-17].

A positive correlation exists between increased nitric oxide $(\mathrm{NO})$ concentration and disease pathogenesis in IBD. Markedly elevated NO levels have been reported in serum, stool and urine of $\mathrm{UC}$ and CD afflicted persons during the active phase of the disease. Therefore, it is considered an inflammatory disease indicating a biomarker in IBD. It has been shown that inducible nitric oxide synthase (iNOS) expression is upregulated by the pro-inflammatory cytokines TNF- $\alpha$, IL-17, IL-23, IL-6, IL-12 and IFN- $\gamma$ in IBD subjects. However, contradictory results have emerged for NO levels in colitic mice that displayed disease amelioration after nitrite administration in dextran sodium sulfate (DSS)-induced colitis. There are reports suggesting heightened disease pathogenicity in IBD through the IL-23/IL-17 axis induced via the NO pathway $[18,19]$. This review examines the numerous research 
studies conducted over the past two decades with a view to linking the distinctly dichotomous nature of the TH17/Treg axis in IBD, as seen in Figure 1.

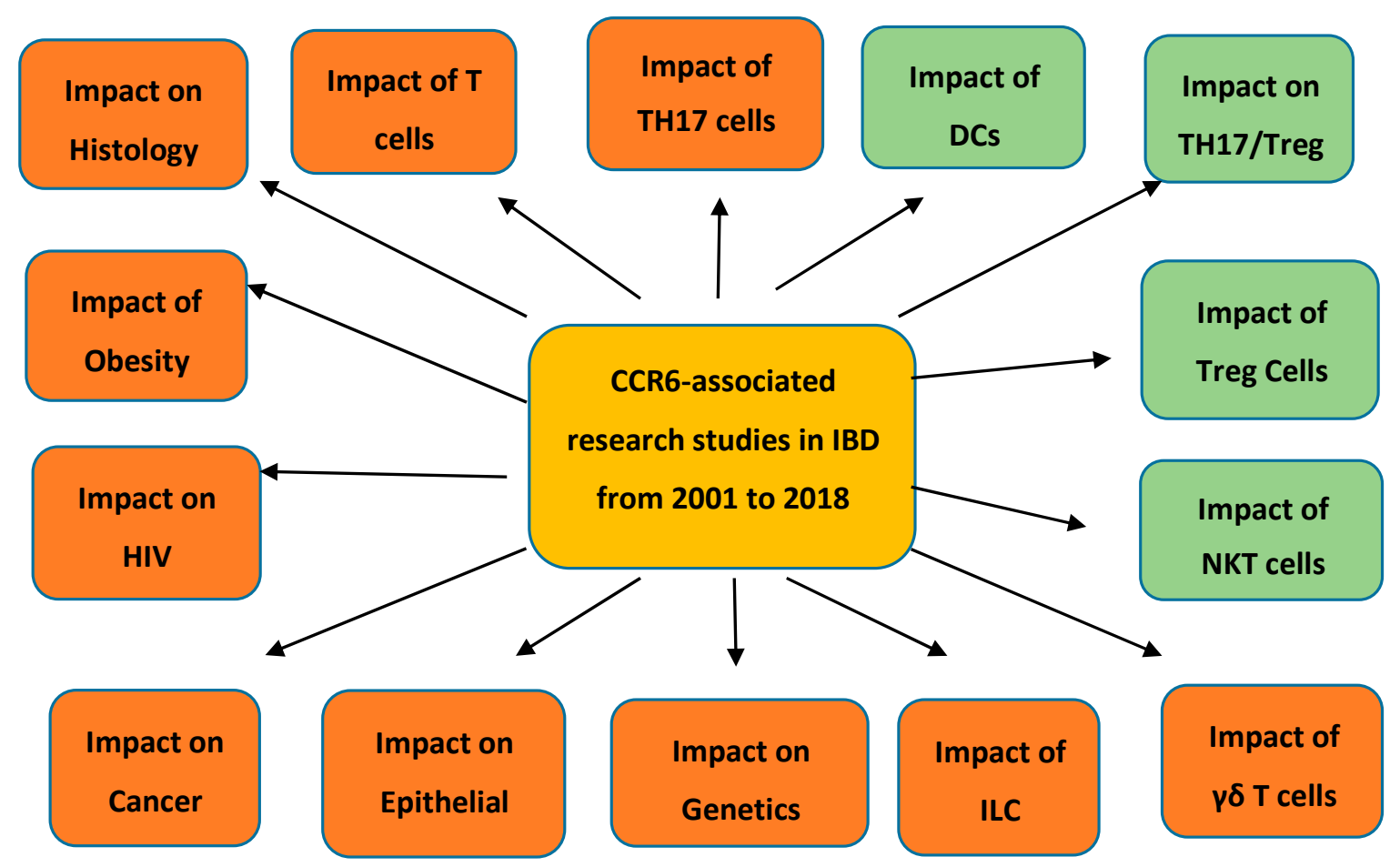

Figure 1. $\square$ Pro-inflammatory analyses; $\square$ Anti-inflammatory analyses. This figure describes both the pro-inflammatory and anti-inflammatory analyses involving the chemokines CCR6 and CCL20 in inflammatory bowel disease (IBD) published by research workers during the time of 2001 to 2018.

\section{CCR6 and Its Role in Potentiating Pro-Inflammatory Properties in IBD}

\subsection{Effect of Chemokines (CCR6 and CCL20) on T Cells in IBD}

The earliest recorded experimental work on the analyses on CCR6 and colitis is in 2001. It was demonstrated that CCR6 expression was suppressed by IL-10, the anti-inflammatory cytokine, by using mice deficient in IL-10 and quantifying messenger ribonucleic acid (mRNA) expressions of several chemokines. The chemokines examined included monokine induced by gamma interferon (MIG), regulated upon activation normal $\mathrm{T}$ cell expressed and secreted (RANTES), macrophage inflammatory protein-3 alpha (MIP-3 $\alpha$ ), T-cell-activation protein-3 (TCA-3), thymus and activation regulated chemokine (TARC), lipopolysaccharide-induced CXC chemokine (LIX), monocyte chemoattractant protein-1 (MCP-1), macrophage inflammatory protein-1 beta (MIP-1 $\beta$ ) and lymphotactin, in which CCR6 and CCL20 were found to be upregulated in IL-10 $0^{-/-}$mice having chronic colitis compared with the wild type (WT) healthy controls. In a second model, they used recombination activating gene 2 (Rag2) ${ }^{-1-}$ mice into which $\mathrm{CD} 4^{+} \mathrm{CD} 45 \mathrm{RB}^{\text {high }} \mathrm{T}$ cells were adoptively transferred during the preliminary stages of colitis and discovered that CCR6 was clearly linked with the acute phase of disease progression. Their findings revealed that chemokines were expressed in both types of mice and were associated with an acute TH1 type immune response. This study showed the significance of the cytokine IL-10 in the CCR6-CCL20 axis as IL-10 was considered to offer a protective role in IBD. IL-10 stimulates the mobilization of the regulatory Treg cell subset within the inflammatory locations in the gut mucosa, thus eliciting an immune suppressive response, leading to reduced inflammation [20].

One of the primary functions of CCR6, the maintenance of leukocyte homeostasis via influencing the cytokine environment, was targeted by Varona and colleagues. They used dextran sodium sulfate 
(DSS)-induced colitis in a murine model deficient in CCR6. DSS-treated CCR6 knockout mice had remarkably reduced intestinal pathology (shortening of the long axis of intestine, thickening of intestinal wall), emphasizing that CCR6 is a compulsory chemokine receptor in determining gut mucosal aberrations, particularly as they showed recovery in between DSS-free periods. WT mice otherwise resistant to tri nitro benzene sulfonic acid (TNBS)-induced colitis became more susceptible to it when CCR6 was deleted. They also showed accumulation of TCR $\alpha \beta$ cells in the gut mucosa with a significant elevation of mRNA by many folds in $\mathrm{CD} 8^{+} \mathrm{T}$ cells compared to $\mathrm{CD} 4^{+}$at the beginning of DSS treatment. Interestingly, in $\mathrm{CCR}^{-/-}$mice, there was no major difference in these $\mathrm{T}$ cell populations during the acute phase of colitis although in the WT the numbers decreased drastically which points to CCR6 being needed for trafficking and limiting T cell populations into the intestinal mucosa during acute IBD. It is widely accepted that CCR6 plays a key role in the mobilization of T lymphocytes, highlighting the role of pro-inflammatory cell types in recent years. The accumulation of $\mathrm{TCR} \alpha \beta$ lymphocytes in the gut during colitis reported by Varona et al. [21] further supports this link. The effect of adhesion molecules and CCL20 expression in the inflamed gut in colitis-afflicted mice was investigated. Inflammation in the gut mucosa is linked to lymphocyte trafficking and associated adhesion molecules such as the mucosal addressin cell adhesion molecule-1 (MAdCAM-1) which is upregulated in the inflamed colonic mucosa in patients suffering from CD and UC. They had employed a murine model of DSS-induced experimental colitis into which fluorescent-labelled T and B lymphocytes taken from the spleen of healthy controls were introduced and lymphocyte adhesion inside colonic micro vessels was observed using an intravital microscope. $\mathrm{T}$ and $\mathrm{B}$ cell adhesion to the colonic vessels was significantly increased in DSS-induced colitis. The use of anti-MAdCAM-1 monoclonal antibodies and anti-CCL20 antibodies or desensitization of CCR6 receptors with excess CCL20 resulted in a remarkable reduction in the accumulation of $\mathrm{T}$ and $\mathrm{B}$ lymphocytes in DSS-induced colitis. The link between the CCR6-CCL20 molecules and the accessory immune apparatus is highlighted in this study. It also reiterates that CCR6 indeed mobilizes lymphocyte migration towards the sites of inflammation, thus aided by vascular adhesion molecules [22].

A TNBS-induced model of Balb/c murine colitis was utilized to investigate the effect of CCL20 secreted by the colonic epithelial cells to determine its impact on T cell activation. They used an anti-CCL20 monoclonal antibody to neutralize CCL20 concentration in the gut to elucidate the effect of CCR6-mediated leukocyte mobilization and recruitment to inflammatory sites in the gut. They observed elevated CCL20 protein levels in diseased mice and that the neutralizing antibody therapy yielded favorable responses (i) in the recovery of ulcers in the mucosa, (ii) lessened histological injury, (iii) reduced myeloperoxidase activity and (iv) decreased colonic weight to length ratio, all of which are characteristics of acute disease. In the acute phase of TNBS-induced disease, a significant increase of CCR6 expressing LP T cell populations $\left(\mathrm{CD}^{+}\right.$and $\left.\mathrm{CD}^{+}\right)$was noted. The monoclonal antibody treatment remarkably reduced these numbers thereby assigning an inflammatory role to CCR6/CCL20 in IBD pathophysiology. Thus the CCR6-CCL20 axis plays a key role in leukocyte trafficking during an inflammatory episode in the gut and suggests that the inhibition or blockade of CCR6 might be a therapeutic approach to IBD [23].

More evidence to support the effects of CCR6 in chronic colitis was demonstrated using a DSS-induced colitic model of G protein-coupled receptor kinase 6 (GRK6) knockout (KO) mice. The activity of GRK6 which regulates the functions of $G$ protein-coupled receptors such as CCR6 was investigated. GRK6 ${ }^{-/-}$and $\mathrm{GRK} 6^{+/-}$mice groups developed severe colitis measured by histological scores, clinical parameters and colon length while keratinocyte-derived chemokine levels, granulocyte infiltration and interleukin-1 beta (IL-1 $\beta$ ) levels were increased with a decrease in the expression of FoxP3 transcription factor proteins in colonic tissue. WT mice had displayed complete recovery whilst the GRK6 deficient mice continued into chronic colitis suggesting the importance of the intracellular kinase GRK6 in determining the disease progression in colitis. The importance of GRK6 indicates the functionality of the CCR6 receptor in recruiting pro-inflammatory Thelper subsets and a simultaneous dampening effect upon the mobilization of the immune suppressive cell subsets during colitis. This is 
an interesting study that explores the activity of GPCR and its direct impact on colitis in a pre-clinical model [24].

$\mathrm{CCR}^{-/-}$mice challenged with oral ovalbumin to develop allergic diarrhea were examined and it was observed that they had protection against disease with a significant decrease in TH2-associated cytokines in the intestine. Further using a T cell transfer model, they demonstrated that CCR6 was required even on the transferred $\mathrm{T}$ cells within the mouse recipients to develop allergic gut disease. This study yet again provides good evidence of the pro-inflammatory behavior of CCR6 which leads to a decrease in the TH2 type inflammatory response when CCR6 gene deletion occurred. CCR6 not only produces TH1 type immunity but also TH2 type of immune response which makes it a chemokine which stimulates and increases inflammatory immune responses [25].

Researching into the activities of chemokines in IBD, it was pointed out that unregulated effector cell responses act as a causative mechanism in the development of mucosal instability during IBD. This effector cell over-activation is said to initiate and sustain inflammation in the gut mucosa and are amply aided by chemokines that help leukocyte adhesion and migration to sites of injury. Among the numerous functions of chemokines, they had listed out the secretion of lipid mediators and reactive oxygen species from leukocytes, matrix release of metalloproteinase, stimulation of tissue fibrosis and tumorigenesis [26].

The chemokine influence of CCR6 and CCL20 on the progression of UC was researched in two groups of patients divided into pediatric onset and adult onset of disease. According to their investigations, CCR6 and CCL20 caused significant tissue damage and disease-related pathology more in pediatric patients, indicating a difference in chemokine functionality and disease onset changing with the age of human subjects [27].

The requisites for $\mathrm{T}$ cell migration within mucosal tissues were recorded and found that in addition to CC chemokine receptor 9 (CCR9) and integrin $\alpha 4 \beta 7$, CCR6 and Neuropilin-1 (Nrp-1), two gut-homing related molecules are needed for the early differentiation of $\mathrm{T}$ effectors within peripheral lymph nodes (pLNs) but not in mesenteric lymph nodes (mLNs). They also revealed that inflammation in the intestine had promoted negative induction of CCR6 and Nrp-1 in pLNs suggesting that localized inflammation in the gut could systematically impact upon T cell differentiation [28].

The severity of experimental colitis depends upon the congenital traits of the mouse models in driving $\mathrm{T}$ cell proliferation. BALB/c mice fed with DSS developed a propensity towards a TH2/TH17/Treg polarized immune mechanisms to seek protection while C57BL/ 6 mice adopted a TH1-polarized inflammatory pathway, becoming more sensitive to DSS-triggered colitis. Whilst it is confirmed that CCR6 and CCL20 molecules together maintain the leukocyte mobilization and activation during inflammation in the gut, there are many other factors such as the genetic, environmental, physiological and immunologic factors which collectively contribute towards inducing an inflammatory micro-environment in the gut mucosa during IBD. However, it is now becoming more evident that the principal function of CCR6 in the gut mucosal compartment happens to be inducing leukocyte migration during inflammation, which in the absence of CCR6 is seemingly reduced and thus it is far better not to produce or promote excessive immune cell mobilization during colitis inflammation. Modulation of the CCR6-CCL20 function would be a worthwhile strategy that needs to be explored to produce a cure phenotype during both acute and chronic disease phases of colitis [29].

\subsection{The Influence of TH17 Cells in IBD}

The TH17 cells have been strongly linked to the inflammatory phase of IBD [30]. CCR6 is described predominantly as a non-lymphoid tissue (intestine) receptor and a homeostatic chemokine receptor, borne by TH17 cell subsets. During an inflammatory episode CCR6 directs T cell migration into the gut mucosa whilst within the secondary lymphoid organs [30]. Using human peripheral blood, adult tonsils (secondary lymphoid tissue) and neonatal cord blood mononuclear cells, CCR6 expression was shown to be on both TH17 and Treg cells. In addition, TH17 cell subsets were also found to 
express TH1- and TH2-associated T cell trafficking chemokine receptors including CXCR6, CCR5, CCR2, CXCR3 and CCR4 [30].

Remarkable observations on TH17 cells were made emphasizing that CCR6 is a signatory receptor of this cell population and it is an important intestine-homing receptor which regulates $\mathrm{T}$ cell migration within the gut tissue microenvironments. It was observed that there was reduced $\mathrm{T}$ cell migration in CCR6-deficient mice into Peyer's patches (PP). Compared to CCR6-deficient mice, the large intestine of the WT expressed normal T cell migration patterns. Reconstitution of severe combined immunodeficiency (SCID) mice with $\mathrm{CCR}^{-/-}$TH17 cells had caused severe aberrant lesions in the gut because, in the absence of CCR6, these cells differentiate into a pro-inflammatory TH1 type. Furthermore, CCR6 expression on TH17 cells was downregulated by IL-2 in both in vitro and in vivo experiments as much as it was upregulated by transforming growth factor-beta (TGF- $\beta$ ). The role of TH17 cells highlights the importance of CCR6 into navigating immune cells to the PP where most of the immune activity takes place in the gut mucosa during an episode of IBD [31].

TH17 CD4 ${ }^{+} \mathrm{T}$ cells co-expressing CCR6 and integrin- $\beta 7$ at the site of inflammation, also express CD161, a C-type, lectin-like receptor known for releasing pro-inflammatory cytokines, IL-17 and IFN- $\gamma$ in the presence of the master cytokine, IL-23 in CD patients. TH17 cells noted for their gut-homing capacity are prone to inducing colitis, confirmed by marked expression of the cytokines IL-17, IL-22 and IL-23 receptors [32].

The master cytokine IL-23 has multiple roles in inducing TH17 responses such as (i) intestinal accumulation of TH17 cells, (ii) suppressing the differentiation of FoxP3 ${ }^{+}$IL-10-producing Treg cells and (iii) stimulating the emergence of a group of IFN- $\gamma^{+}$IL-17A ${ }^{+} \mathrm{T}$ cells. IL23R gene mutations is well known to enhance susceptibility to IBD [33]. The importance of IL-23 in UC was described where increased mucosal expression of $I L-23 p 19$ gene was positively correlated to increased IL-23 serum levels [34].

TH17 cells were further evaluated using an anti-CD3 antibody-induced tolerance model, a sepsis model and a viral infective model to study their characteristic behavior in driving antigen-specific intestinal pathology in the small intestine. TH17 cells deliver two different mechanisms; they become eliminated across the gut lumen and secondly, they are transformed into an immune-suppressive phenotype described as " $\mathrm{rT}(\mathrm{H}) 17$ " both in vitro and in vivo. Both these mechanisms function to delimit the TH17 cell populations in the gut, thereby regulating pathogenicity in the gut mucosa. This study has identified mechanisms which act to regulate the accumulation of TH17 cells in the gut mucosa, thus indicating a self-activated delimiting process of the TH17 cells which could initiate a decrease in the inflammatory response and it may be how immune suppression is achieved during resolution of the disease [35].

Genomic loci within $\mathrm{CD}^{+}$memory T cells and particularly in the TH17 compartment which are linked to immune-mediated diseases were examined, using RNA sequencing and promoter methylation studies. IL17A and CCL20 were genes solely expressed by TH17 cells and increased promoter methylation was correlated to negligible RNA sequence levels in them. The study concluded that the gene expression in $\mathrm{T}$ cell subsets combined with disease-related signals give an insight into the pathways promoting immune-compromised pathogenicity. DNA methylation, which is the addition of methyl groups to the promoter region of the gene of interest, is known to repress transcription of certain genes. Thus, DNA methylation of the gene promoter may hold the key to switching off certain undesirable cell subsets or their pro-inflammation-inducing molecules such as CCR6 on the TH17 cells during acute inflammation in the gut mucosa [36].

IL-1 $\beta$ was identified as a critical cytokine that avails CCR6 ${ }^{+}$CXCR3 $^{+}$TH17 cells sensitive to IL-12. Both IL-1 $\beta$ and IL-12 together induced the differentiation of TH17 into a population that secretes IFN- $\gamma$, IL-17 and GM-CSF during a pathogenic episode. Those TH17 cells were of TH1/17 type and expressed the gut-homing receptor, integrin $\beta 7$ and receptors capable of recognizing extracellular bacteria. They concluded that this cellular subset was specific for microbial-induced pathogenesis. It is now established that there exist subpopulations of the pro-inflammatory TH17 cells which can 
influence the immune responsiveness during gut inflammation. This study demonstrates the possible secretion of different types of cytokines by these subpopulations which may act to modulate the disease outcome, and they may possibly initiate different signaling networks within the gut mucosal system [37].

A novel TH17 cell subset named the suppressor TH17 which produces immune suppressor activity in patients with CD was reported by Huang in 2015 [38]. The interesting feature gathered from these results is that they are generated from induced Treg cells (iTreg) when these cells are exposed to conditions that favor TH17 activation. Suppressor TH17 have been detected to express a membrane-bound catalytic protein, CD 39, which generates nucleosides such as adenosine from pro-inflammatory extracellular nucleotides. The suppressor TH17 cell type is present in healthy peripheral blood and the LP but appear to rigorously decrease in CD patients. CD 39 is known to catalyze the breakdown of extracellular adenosine triphosphate (eATP) produced during an event of inflammatory stress or tissue injury in autoimmune disease or chronic inflammation. The fact that the CD 39 levels are diminished in Crohn's patients is consistent with its catalytic function not being at its maximum and underpins its importance as a molecule associated with immune suppression in the inflamed intestinal mucosa [38].

The effect of unconjugated bilirubin (UCB), which is formed because of haem oxidation, on experimental colitis was investigated as it has known protective immune suppressive properties. Immune suppressive effects of UCB is mediated by the aryl hydrocarbon receptor (AHR) ligated to TH17 cells which also upregulate CD39 and FoxP3. In IBD, they reported negligible immune suppressive effects of UCB upon TH17 cells owing to reduced AHR levels in vitro. However, the conclusion was that boosting of CD39 immune innervation or the UCB-induced AHR pathway could provide substantive therapeutic outcomes to overcome TH17 dysfunction in IBD. AHR is a protein sensor of plant-derived phytochemicals and provides a direct link between the diet and disease during colitis. It also mediates and maintains ROR $\gamma \mathrm{t}^{+}$innate lymphoid cells in the gut [39].

In studying the pathways adopted by lymphocytes to perform their effector functions, the B cell-activating transcription factor (Batf) expressed on $\mathrm{T}$ cells acts as an important regulator of TH17 cells during their developmental stages and is strongly expressed in intestinal tissue during IBD. Batf positive T cells are thought to actively contribute to the T cell-mediated component of colitis. Further, unlike STAT3, the absence of Batf did not influence the intestinal homeostasis ex vivo. B cell activating factor acts as a ligand to one of the receptors of the TNF- family cytokines and the overproduction of Batf is associated with systemic autoimmune disease. This indicates that neutralizing Batf would provide means of reducing T cell-mediated inflammatory responses, particularly those of the TH17 type [40].

\subsection{The Influence of Gamma Delta $(\gamma \delta)$ T Cells in IBD}

An interesting aspect of gamma delta $(\gamma \delta) \mathrm{T}$ cells is their ability to differentiate into two-different lineages upon acquiring the ability to produce cytokines that occur within the thymus. The two-different cell population expresses two mutually exclusive receptors, namely CCR6 and natural killer 1.1 (NK1.1). The CCR6 expressing $\gamma \delta \mathrm{T}$ cells acquired an IL-17A releasing phenotype while the NK1.1 bearing subset was prone to produce IFN- $\gamma$ with or without T cell receptor (TCR) dependent stimuli [41].

The inflammatory potential of a new subset of CD4 T cells, namely the IL-17 expressing $\gamma \delta \mathrm{T}$ cells, was discovered to be responsible for driving TH17 cell differentiation and, therefore, T cell innervated colitis. Mice deficient in the receptor TCR $\beta \gamma$ displayed resistance to disease whilst TCR $\beta$-deficient mice became susceptible. However, simultaneous reconstruction with IL-1 $7^{+} \gamma \delta \mathrm{T}$ cells and CD4 T cells had made TCR $\beta \gamma$-deficient mice to produce severe colitis, thereby suggesting that IL- $17^{+} \gamma \delta \mathrm{T}$ cells have the capacity to induce intense intestinal pathology by supporting TH17 subset differentiation, in vivo [42]. 


\subsection{The Influence of CCR6 $6^{+}$Innate Lymphoid Cells (ILC) in IBD}

A novel cell lineage identified as innate lymphoid cells (ILC) which release the cytokines IFN- $\gamma$, IL-17 and IL-22 when stimulated by IL-23 were shown to mediate intestinal pathology in colitis mice. Based on the release of cytokines these cells were named ILC1, ILC2 and ILC3. ILCs are characterized by the absence of lineage-specific nuclear receptors and antigen-specific $\mathrm{B}$ and $\mathrm{T}$ cell receptors. They also lack myeloid and dendritic cell markers, and yet mediate immune homeostasis and regulate inflammation during autoimmune disease conditions [43].

A significant increase in $\mathrm{CD} 127^{+} \mathrm{CD} 56^{-}$ILC in the intestine of $\mathrm{CD}$ subjects has been observed but not in those having UC. CD56 ILC had released IL-22 and IL-26 when stimulated by IL-23, and CD56 negative ILC expressed IL-17A-F indicating the functional axis of the IL-23/IL-17 pathway in IBD. ILC are involved in triggering inflammation in the gut via cytokine release and recruitment of lymphocytes in mice enduring colitis [43].

Hepworth et al. recently demonstrated the involvement of CCR6 ${ }^{+}$major histocompatibilitycomplex class II $\left(\mathrm{MHCII}^{+}\right)$ILC3 directly mediating the cell death of activated T cells which induce tolerance towards commensal microbial flora in the gut. In pediatric patients, these colonic ILC3 cells expressed reduced MHCII [44].

\subsection{The Effect of CCR6 ${ }^{+}$Intestinal Epithelial Cells on IBD}

It is an established fact that CCL20 is produced by the intestinal epithelial cells in copious amounts in direct response to microbial stimulation. CCL20 is well known for its effect on leukocyte recruitment of CCR6-expressing immune cells to the gut mucosa and the maintenance of the epithelial barrier integrity. An investigation on CCL20 using Caco-2 and HT-29 human colonic cell lines, the researchers demonstrated elevated mRNA levels after the analysis of colonic tissue stating that IL-1 $\beta$ and TNF- $\alpha$ stimulated the release of CCL20 in a dose-dependent manner. CCL20 expression in patients afflicted with Crohn's disease (CD) was found to be significantly increased in the primary epithelium compared to healthy controls or those having ulcerative colitis (UC). CCL20 was essentially raised in the human intestine paving way for mobilization and recruitment of lymphocytes during IBD [45].

In UC, which is like CD, CCL20 gene expression was shown to be upregulated and correlated with disease progression. UC patients undergoing remission showed reduced CCL20 expression levels. Peripheral blood mononuclear cells (PBMC) obtained from UC patients had exhibited upregulated CCL20. mRNA of CCL20 in patients with UC was quantified compared with healthy controls where increasing CCL20 levels were correlated with disease progression. A follow-up study after 3 months revealed that CCL20 mRNA was severely reduced in PBMC followed by disease amelioration in those who were treated with glucocorticoid and 5-aminosalicylic acid-containing drugs indicating that CCL20 levels are modulated by anti-inflammatory medication. Further, HT-29 cells obtained from the human intestinal epithelium showed markedly reduced CCL20 secretion when treated with anti-inflammatory drugs which is otherwise induced by the pro-inflammatory cytokines, IL-1 $\beta$ and TNF- $\alpha[46]$.

The link between chemokines and leukocyte recruitment into inflamed gut mucosa in IBD is well described. A microarray gene expression patterns of active IBD patient colons presented CCL20 as an important molecule indicating the potential role in IBD pathogenesis. CCL20 as well as CXCL 1-3 and 8 along with the receptors, CCR6, CXCR1 and 2 were found to be distinctive in the acute phase of colonic IBD. An examination of Caco-2 and HT-29 cell lines had shown a similar expression of these chemokines when stimulated by IL- $1 \beta$. Caco- 2 cells were unresponsive to TNF- $\alpha$ although both IL- $1 \beta$ and TNF- $\alpha$ synergistically activated HT- 29 and primary keratinocytes indicating that these two cytokines prominently influence the epithelial chemokine expression in inflamed tissue of IBD patients $[10,47]$.

The role of CCR6 in wound healing has been described. In this study, IL-23 secreted by the epithelial cells was found to be a major player in bringing $\mathrm{CCR} 6^{+}$cells to the gut mucosa. Lymphotoxin beta receptor (LTBR) signal transduction in the gut epithelium promotes intestinal homeostasis by 
wound healing and self-repair after an epithelial injury. The cue for this process is provided by IL-23 produced by the epithelial cells. IL-23 induces IL-22-mediated, cell proliferation and increased mucous secretion by a group of lymphoid tissue inducer cells expressing CCR6 and ROR $\gamma \mathrm{t}$. This study demonstrates the contribution made by the intestinal epithelium towards maintaining immune homeostasis in the gut [48].

The CCL20 production by the intestinal epithelial cells (IEC) in CD subjects, which was supposed to be very high due to increased TNF- $\alpha$, was examined and recorded that it was decreased upon TGF- $\beta 1$ induction, but this effect was reversed by a similar method to mothers against decapentaplegic 7 (Smad7) antisense oligonucleotide which is normally elevated in CD patients. Several studies have described a positive correlation between TNF- $\alpha$ and CCL20 [49]. In CD, increased TNF- $\alpha$, directly correlates with increased CCL20 production in the epithelial cells. This in fact could be reversed by TGF- $\beta$ [49]. During an episode of CD, Smad7 has been shown to downregulate TGF- $\beta 1$ which causes negative regulation of TNF- $\alpha$ signaling, which is said to be responsible for inflammatory induction. Via the negative control of TGF- $\beta$, Smad7 brings about lowered production of CCL20 in serum during CD. This study demonstrates the relationship between the molecules of Smad7, CCL20, TNF- $\alpha$, TGF- $\beta 1$ and CD. It is interesting to note which mechanisms upregulate the expression of CCL20, which is the focus of our interest, and it is also known to increase its production during inflammation. It is established that TNF- $\alpha$ is a pro-inflammatory cytokine, whilst TGF- $\beta 1$ is one which induces the release of the immune suppressive cytokine IL-10 [49].

The effect of CCR6 deficiency affects B cell production and its related activity in PP and germinal centers resulting in lowered generation of immunoglobulin A (IgA) memory B cells, impaired IgA class switching ability and decreased affinity to IgA. Further, decreased numbers of ILC within isolated lymphoid follicles (ILFs) bring forth a marked reduction in IL-22 secretion which negatively impacts upon anti-microbial peptide production by the IEC. Absence of CCR6 functionality also leads to higher levels of Alcaligenes in PP and filamentous bacteria thriving within the epithelium, thus delineating a role for CCR6 in regulating intestinal symbiotic relationships [50].

\subsection{The Impact of CCR6 Expression on Colonic Histology}

CCR6 has been described as an important factor for the histological development of the intestinal mucosa. Studies utilizing CCR6-enhanced green fluorescent protein knock-in mouse models clearly show that CCR6 is needed for PP development. Additionally, CCR6 deficiency led to a proportional decrease in $\mathrm{T}$ and $\mathrm{B}$ cells with specific reduction in regulatory $\mathrm{T}$ cells. Other structures in the intestine affected by CCR6 deficiency include microfold (M) cells within the follicle associated epithelium (FAE). Overall with CCR6 deficiency, the intestinal architecture shows significant changes including the malformation and the retarded growth of the gut [51].

A study using CCR6 KO mice reported that $\mathrm{CCR}^{+} \mathrm{B}$ cells are recruited into crypto patches $(\mathrm{CPs})$ in the intestinal mucosa and their expansion allows the CPs to differentiate into ILF. It was observed that the developmental defects in intestinal morphology obvious in CCR6 KO mice become responsible for reduced IgA secretion against oral antigens. Furthermore, the effect of CCR6 deficiency on B lymphocytes leads to associated B lymphocyte pathophysiology, thus influencing the tissue development in the gut [52].

Research into the immunogenic role of CCR6 utilizing a pathogenic bacterium, Yersinia enterocolitica, has shown that this infection in CCR6-deficient mice produced limited symptoms whereas in control mice lethal severe lesions were produced. The research demonstrated the use of $\mathrm{M}$ cells present in PP as conduits for the penetration of the mucosal barrier by these microbes underscoring the importance of CCR6 deficiency and its relationship with microbial uptake by M cells. Through analysis by immunohistochemistry, the researchers had discovered the invasion of PP by Yersinia in control mice which was also augmented by pro-inflammatory cytokines whilst bacteria were completely absent in the intestinal tissues of $\mathrm{CCR} 6^{-/-}$mice. It is to be noted that both groups of mice showed equal susceptibility when infected via the intraperitoneal route [53]. 
An evaluation of CCL20 expression in individuals suffering from prolonged UC using immunohistochemistry (IHC) recorded a significant elevation in CCL20 biomarker in the rectal mucosa correlating the IHC scores with the development of UC-related neoplasia. This study provided evidence of chemokines released by the colonic epithelium being important for maintaining and repairing the epithelial barrier because prolonged inflammation is a proven risk for developing malignant diseases in the gut [54].

\subsection{CCR6 Association with Colitis and Colorectal Cancer}

Studies have described CCR6 is an important marker for maintaining intestinal homeostasis and CRC metastasis [55]. CCR6 is specifically expressed by normal IEC but also by colorectal cancer $(C R C)$ cells. When IEC are stimulated with CCL20 in a pro-inflammatory cytokine setting of TNF- $\alpha$, IL-1 $\beta$ and lipopolysaccharide (LPS), its mRNA expression is markedly upregulated. Synonymous with the observation that CCL20 mRNA is remarkably high in the colonic tissue of CD patients, it was also correlated to increased IL-8 mRNA expression in their lesions. They suggested that CCR6 modulates cell proliferation and cell migration via CCL20-activated migratory pathway of extracellular signal-regulated kinases $1 / 2$ (ERK 1/2), stress-activated protein kinase/jun kinase (SAPK/JNK) and protein kinase $\mathrm{B} /(\mathrm{Akt})$ signal transduction in IEC and CRC cells. [55].

CCR6/CCL20 chemokines are described as a critical link between non-malignant UC and malignant colorectal diseases, through quantifying mRNA and protein profiles using reverse transcription polymerase chain reaction (qRT-PCR), enzyme-linked immunosorbent assay (ELISA) and IHC. It is well established that cancer cells use CCR6 for its metastatic spread, and in this study, resection tissue specimens were observed from patients having UC, colorectal adenoma (CRA), colorectal adenocarcinoma (CRC) and colorectal liver metastases (CRLM) compared with healthy tissue confirming the link that CCR6 is used by cancer cells for metastatic spread. CRA, CRC and CRLM exhibited specific upregulation of CCR6/CCL20 proteins, suggesting a definite association between these chemokines and colorectal carcinoma [56].

In another study, the effect of CCR6 and its ligand in colonic carcinoma was investigated using a CCR6-deficient mouse model into which colon cancers were adoptively transplanted. Tumorigenesis was found to be associated with increased macrophage infiltration and the depletion of such macrophages weakened tumor growth in the transplanted tumor model. It is also known that CCL20 promotes monocyte migration into tissues in vitro and the gathering of macrophages within the tumors in vivo. CCR6 deficiency in the host exhibits reduced tumorigenesis in syngeneic CCR6-expressing colonic cancers. All the above described findings confirm the fact that CCR6 plays a key role in the growth and metastatic spread of many different cancer types in the human body, and importantly, CCR6 functional mechanism of mobilizing immune cell types seems to directly aid the development of colorectal cancer from excessively inflamed colonic mucosal tissue [57].

\subsection{The Impact of CCR6 ${ }^{+} T$ Cells in the Gut on Human Immunodeficiency Virus (HIV)}

The capacity of CCR6 ${ }^{+} \mathrm{T}$ cells to induce permeability to HIV was recorded via a newly recognized HIV-gp120 binding receptor which happens to be $\alpha(4) \beta(7)$ integrin, vital for gut-homing in the gut-associated lymphoid tissue (GALT). T cells expressing combined CCR6 and integrin $\beta(7)$ could propagate HIV and the mechanisms of differentiation of the memory T cells positive for CCR6 are crucial when targeting therapeutic interventions to treat HIV [58].

\subsection{The Effect of $\mathrm{CCR} 6^{+}$Cells in the Gut on Obesity}

A link between obesity, inflammation and the role of CCR6 in it is demonstrated by recent research work [59]. Excessive mobilization of immune cells and the associated cytokine release causing inflammation in the gut is increased by obesity because the adipose tissue lymphocytes that express CCR6 are attracted towards mature adipocytes which produce significant amounts of CCL20 [9]. CCR6 expressing B cells and $\gamma \delta$ T cells are avidly recruited by CCL20 polarized lymphocyte migration 
to the gut. Obesity has been shown to induce IL-6 secretion which enhances the proliferation of tumor-promoting macrophages that release CCL20. Wunderlich et al. additionally showed that dietary-induced obesity could leave colitis patients at a higher risk of developing cancer via increased recruitment of inflammatory immune cells to the gut which promotes active inflammation $[9,59]$.

\section{CCR6 and Its Role in Potentiating Anti-Inflammatory Properties}

\subsection{The Effect of Regulatory Treg Cells in IBD}

CCR6 is explicitly needed for Treg-modulated immune suppression of colitis to direct IL-10-releasing, antigen-specific iTreg cells to the colon of diseased mice as indicated by supplementation of Rag 2 deficient mice, with CCR6 deficient $\mathrm{CD} 4^{+} \mathrm{T}$ memory cells leading to exacerbation of colitis, with elevated production of IFN- $\gamma[60]$.

Rivino and colleagues demonstrate that CCR6 expressing $\mathrm{CD}^{+}$memory $\mathrm{T}$ cells differentiate into two cohorts of IL-17 and IL-10 releasing TH17 and Treg cells, respectively. Both the types were induced by TGF- $\beta$ whilst the IL-10-stimulated suppression of the tolerogenic Treg cells was abrogated by IL-2 in a colony of autologous immature myeloid dendritic cells cultured ex vivo [61].

A new term, namely the "inflammatory" Treg cells, was introduced after investigating the attributes of a small subset of FoxP3 ${ }^{+}$IL-17 expressing CD4 T cells in human peripheral blood. Such cells become pathogenic in UC-afflicted patients by stimulating the release of inflammatory cytokines and halting $\mathrm{T}$ cell-mediated immune responses. Furthermore, these cells have similar characteristics as that of TH17 and Treg cells in a co-existing fashion and arise from the differentiation of $\mathrm{CCR}^{+} \mathrm{CD} 4 \mathrm{~T}$ memory cells which require priming by IL-2, TGF- $\beta$ and APCs of myeloid origin [62].

Another subset of regulatory T cells identified as TGF- $\beta$-induced IL- $8^{+}$FoxP3 ${ }^{+} \mathrm{T}$ cells was described as consisting of mostly naïve T cells expressing CD 127 which are capable of both immune-suppressive and inflammatory roles. $\mathrm{T}$ cell proliferation and the production of cytokines which initiate effector functions were inhibited by this subset whilst IL-8 induced inflammatory cytokine release and neutrophil infiltration were recorded. This study labelled the aforementioned cells as an inflammatory Treg subgroup which could initiate tumor development in an inflammatory setting such as the development of CRC from chronic UC [63].

The non-chemotaxis functions of the CCR6-CCL20 axis were investigated by Kulkarni et al. and recorded (i) negative correlation with $\mathrm{FoxP}^{+} \mathrm{CD}^{+} \mathrm{T}$ cells in $\mathrm{UC}$ subjects compared to healthy controls; (ii) Tregs positive for CCR6 had enhanced ROR $\gamma t$ expression compared with CCR6 negative Tregs; (iii) TGF- $\beta 1$-induced iTreg differentiation was abrogated by CCL20 and channeled towards transforming into pro-inflammatory TH17 type; (iv) impaired suppression of the surface molecules CD39, CD73, Fas ligand (FasL) expressed on iTreg cells in the presence of CCL20; and (v) CCR6-induced phosphorylation of the molecules Akt, STAT3 and mammalian target of rapamycin (mTOR) in T cells [64].

Godefroy and co-workers in 2018 report a newly identified T cell subset named CD4 $4^{+} / \mathrm{CD} 8 \alpha^{+}$ or double positive 8 alpha cells (DP8 $\alpha$ cells) which reportedly express CCR6 and proliferate when stimulated by a gut-inhabiting faecal microbe, Faecalibacterium prausnitzii, a firmicute of the Clostridium IV group. These microbes are said to be low in numbers in IBD patients but in healthy individuals they promote the release of the cytokine, IL-10 and inhibit T cell proliferation in a CD39-dependent pathway [65].

In summary, the characteristic role of the regulatory Treg cells that express CCR6, that are induced by the cytokines TGF- $\beta$, IL-35 and IL-10, is to produce immune suppression in the gut during an inflammatory episode such as colitis [9].

\subsection{The Influence of TH17/Treg Balance in IBD}

CCR6 expression on TH17 is induced by the cytokine TGF- $\beta$ and transcription factors ROR $\alpha$ and ROR $\gamma$. Along with CCR6, TH17 synergistically secretes its ligand CCL20 thus contributing towards 
chemotaxis of TH17 cells towards inflammatory sites. CCL20 expression is induced by TGF- $\beta$, IL-6, IL-21 and requires ROR $\gamma$ and STAT3 transcription factors. In addition, induced regulatory T cells (iTreg) and natural regulatory T cells (nTreg) have been shown to upregulate CCR6 expression, by which disease amelioration is brought about via their immune suppressive functions. The highlight of this research was reiterating the importance of CCR6-driven immune cell migration to inflamed sites, thereby modulating the disease outcome in both autoimmune and inflammatory disorders [66].

The concept of the TH17/Treg equilibrium paradigm was laid down by Lochner and group, and most researchers in recent years have believed it is a factor that determines the pathological outcome in IBD. They describe the co-existence of IL- $17^{+} \mathrm{T} \alpha \beta$ cells expressing ROR $\gamma \mathrm{t}$ induced by the cytokines IL- 6 and IL-23 with FoxP3 ${ }^{+}$IL-10 producing regulatory Treg cells. Moreover, they had established that the ratio of $\mathrm{IL}_{-}-17^{+}$to FoxP3 ${ }^{+} \mathrm{ROR} \gamma \mathrm{t}^{+}$CCL2 $0^{+} \mathrm{T} \alpha \beta$ cells remains constant in ROR $\gamma t$-green fluorescent protein (GFP) transgenic mice afflicted with inflammation and infection [67].

Chaudry et al. add more validation to the TH17/Treg imbalance hypothesis by demonstrating that Treg cells restrain TH17 immune responses in colitogenic mice in a STAT-3 dependent process. STAT-3 is a TH17-specific nuclear receptor which is crucial for the differentiation of TH17 cells and Treg-specific ablation of this receptor resulted in the loss of the immune-suppressive role of Treg cells which is thought to adapt to its environment by producing lethal intestinal lesions [68].

\subsection{The Effect of CCR6 on Dendritic Cells (DC) in IBD}

CCR6 is described as a receptor involved in recruiting DC and memory T lymphocytes into lymphoid follicles in the intestinal mucosa whereas CCL20 was identified in follicle-associated epithelium. Large numbers of immature DCs positive for the marker Langerin were found to accumulate in subepithelial space. A salient feature of this study was that TNF- $\alpha$ induced CCL20 secretion in the healthy controls whilst anti-TNF- $\alpha$ acted to decrease it. This study elegantly illustrated the contribution of CCL20 in regulating the mobilization of T lymphocytes and antigen-sampling cell populations into the gut mucosa during IBD [69].

In another study involving umbilical cord blood-derived CD $34^{+}$mononuclear cells, which are a subset of human Langerhans cells (LC), the immunogenic mechanisms of CCR6 and CCL20 and the involvement of cytokine mediated immunity were demonstrated. LC are described as a unique sub cohort of dendritic cells (DC) accumulating on epithelial surfaces and eliciting immune responses. IL-10, the key anti-inflammatory cytokine which is notable for the induction of regulatory $\mathrm{T}$ reg cells, was found to upregulate CCR6 expression during LC development. When IL-10 influence was withdrawn, CCR6 failed to maintain its expression during the maturation of DC while IL-4 and IFN- $\gamma$ directly acted to block CCR6 expression as well as having the ability to respond to CCL20 during different stages of LC development. The recruitment of LC to the epithelial surface was quelled by TH1/TH2 inflammatory pathways while it was consistently promoted by IL-10 and TGF- $\beta$-induced tolerogenic immunity [70].

DCs are important for antigen sampling, pathogen recognition and priming of naïve $\mathrm{T}$ lymphocytes into effectors and thereby initiating $\mathrm{T}$ cell activation during adaptive immune responses. The importance of CCR6-expressing DCs in mobilizing and activating T lymphocytes was demonstrated, specifically in the subepithelial domes in PP in response to pathogen activation by Salmonella typhimurium in a C57BL/6 murine model. In contrast, CCR6-deficient DCs failed to mount such a response to activate $T$ cells resulting in decreased immunity against an oral infection of invasive enteric bacteria. This specific study used mouse strains having CCR6 enhanced by green fluorescent protein or a deletion of CCR6 to be induced by CCL20 and bacterial flagellin-specific TCR transgenic mice to identify DC subsets which stimulate T cells in PP and an inducible diphtheria toxin system for the depletion of DCs. CCR6 ${ }^{+}$DCs mediate localized T cell activation in the PP and CCR6 deficiency impairs activation of $S$. typhimurium antigen specific $\mathrm{CD} 4^{+} \mathrm{T}$ cells by those DCs [71].

More information supporting the DC infiltration to inflammatory sites in the gut is described in UC afflicted patients demonstrating a positive correlation between immature CCR $6^{+}$DCs and the level 
of inflammation in the crypts of colonic mucosa. They found a validated positive relationship between crypt atrophy and mononuclear cell infiltration during active inflammation. Their observations included the clustering of S-100 protein ${ }^{+} \mathrm{CCR} 6^{+}$MIP- $3 \alpha^{+}$DCs becoming localized within crypts when they were inflamed using histological scores, immunohistochemistry and mRNA analyses suggesting that CCR6 expressing DCs play a significant role in inducing crypt inflammation [72].

E-cadherin is the receptor for CD103 and is known to promote inflammation in the intestine. E-cadherin expressing DCs gather inside mesenteric lymph nodes, express toll-like receptors and produce pro-inflammatory cytokines IL-6 and IL-23 during an inflammatory incident in the intestine. It is already known that $\mathrm{CD} 103^{+} \mathrm{DCs}$ in the gut promote regulatory immune responses of Treg cells but the transfer of E-cadherin ${ }^{+} \mathrm{DC}$ s into immune-deficient mice reconstituted with $\mathrm{T}$ cells has produced TH17 immune responses leading to worsening of intestinal colitis. Therefore, these monocyte-derived DCs positive for E-cadherin are a potential therapeutic target in IBD [73].

\subsection{The Influence of Natural Killer T (NKT) Cells}

Hornung et al. demonstrated the ability of DX5 ${ }^{+}$Natural Killer T (NKT) cells to attenuate colitis in Balb/c mice when transferred from healthy mice to SCID mice where they were later detectable in MLN after adoptive transfer. A fluorescence-activated cell sorter (FACS) had identified the expression of a repertoire of chemokine receptors on this cell subpopulation involved in migration in vivo, among which CCR6 was also present [74].

\section{Future Directions}

In reviewing the CCR6-CCL20 biology and its immune mechanisms in IBD, we have condensed about 60 different studies spanning nearly 18 years into a comprehensive analysis. We have described both the pro-inflammatory and anti-inflammatory effects of the CCR6-CCL20 axis. Most of the results obtained have utilized multiple animal models which may not be a true depiction of human colitis. Therefore, pre-clinical studies involving relevant IBD animal models (spontaneous colitis) or human tissue (organoids and spheroids) would be more advantageous. Investigations into novel paradigms such as ILC behavior, ER stress, gut-specific microbiome, intestinal apoptosis, and metabolomics need to be encouraged with special reference to CCR6 mediation. Goal-oriented, specifically targeted innovative research models are needed to construct the bigger picture behind the CCR6-CCL20 immune modulatory scenario that will open avenues to test more effective therapeutic interventions to treat IBD in the future.

Author Contributions: Concept, researching and writing: R.R.; advice, writing and editing: R.E.

Acknowledgments: The first author is funded by a research training program (RTP) scholarship given by the Australian Government. This research received no external funding. English language editing by Dominic Geraghty is thankfully acknowledged.

Conflicts of Interest: The authors declare no conflict of interest.

\section{References}

1. Graham, D.B.; Xavier, R.J. From genetics of inflammatory bowel disease towards mechanistic insights. Trends Immunol. 2013, 34, 371-378. [CrossRef] [PubMed]

2. Shouval, D.S.; Rufo, P.A. The role of environmental factors in the pathogenesis of inflammatory bowel diseases: A review. JAMA Pediatr. 2017, 171, 999-1005. [CrossRef] [PubMed]

3. Rosen, M.J.; Dhawan, A.; Saeed, S.A. Inflammatory bowel disease in children and adolescents. JAMA Pediatr. 2015, 169, 1053-1060. [CrossRef] [PubMed]

4. Kaser, A.; Zeissig, S.; Blumberg, R.S. Inflammatory Bowel Disease. Annu. Rev. Immunol. 2010, 28 , 573-621. [CrossRef] [PubMed]

5. Friedrich, M.J. Inflammatory bowel disease goes global. JAMA 2018, 319, 648. [CrossRef] [PubMed] 
6. Niewiadomski, O.; Studd, C.; Hair, C.; Wilson, J.; Ding, N.S.; Heerasing, N.; Ting, A.; McNeill, J.; Knight, R.; Santamaria, J.; et al. Prospective population-based cohort of inflammatory bowel disease in the biologics era: Disease course and predictors of severity. J. Gastroenterol. Hepatol. 2015, 30, 1346-1353. [CrossRef] [PubMed]

7. Crohn's and Colitis Foundation Australia Website. 2013. Available online: http:/ /www.crohnsandcolitis. com.au (accessed on 21 July 2018).

8. Niewiadomski, O.; Studd, C.; Wilson, J.; Williams, J.; Hair, C.; Knight, R.; Prewett, E.; Dabkowski, P.; Alexander, S.; Allen, B.; et al. Influence of food and lifestyle on the risk of developing inflammatory bowel disease. J. Intern. Med. 2016, 46, 669-676. [CrossRef] [PubMed]

9. Ranasinghe, R.; Eri, R. Pleiotropic immune functions of chemokine receptor 6 in health and disease. Medicines 2018, 5, 69. [CrossRef] [PubMed]

10. Basheer, W.; Kunde, D.; Eri, R. Role of chemokine ligand CCL20 and its receptor CCR6 in intestinal inflammation. Immunol. Infect. Dis. 2013, 1, 30-37.

11. Lee, A.Y.S.; Eri, R.; Lyons, A.B.; Grimm, M.C.; Korner, H. CC chemokine ligand CCL20 and its cognate receptor CCR6 in mucosal $\mathrm{T}$ cell immunology and inflammatory bowel disease: Odd couple or axis of evil? Front. Immunol. 2013, 4, 194-206. [CrossRef] [PubMed]

12. Lee, A.Y.S.; Phan, T.K.; Hulett, M.D.; Korner, H. The relationship between CCR6 and its binding partners: Does the CCR6-CCL20 axis have to be extended? Cytokine 2015, 72, 97-101. [CrossRef] [PubMed]

13. Lu, M.Y.; Lu, S.S.; Chang, S.L.; Liao, F. The phosphorylation of CCR6 on distinct Ser/Thr residues in the carboxyl terminus differentially regulates biological function. Front. Immunol. 2018, 9, 415. [CrossRef] [PubMed]

14. Lee, S.H.; Kwon, J.; Cho, M.L. Immunological pathogenesis of inflammatory bowel disease. Intest. Res. 2018, 16, 26-42. [CrossRef] [PubMed]

15. Neurath, M.F. Cytokines in inflammatory bowel disease. Nat. Rev. Immunol. 2014, 14, 329-342. [CrossRef] [PubMed]

16. Guan, O.; Zhang, J. Recent advances: The imbalance of cytokines in the pathogenesis of inflammatory bowel disease. Mediat. Inflamm. 2017. [CrossRef] [PubMed]

17. Strober, W.; Fuss, I.J. Pro-inflammatory cytokines in the pathogenesis of IBD. Gastroenterology 2011, 14, 1756-1767. [CrossRef] [PubMed]

18. Soufli, I.; Toumi, R.; Rafa, H.; Touil-Boukoffa, C. Overview of cytokines and nitric oxide involvement in immune-pathogenesis of inflammatory bowel diseases. World J. Gastrointest. Pharmacol. Ther. 2016, 7, 353-360. [CrossRef] [PubMed]

19. Rafa, H.; Saoula, H.; Belkhelfa, M.; Medjeber, O.; Soufli, I.; Toumi, R.; de Launoit, Y.; Morales, O.; Nakmouche, M.; Delhem, N.; et al. IL-23/IL-17A axis correlates with the nitric oxide pathway in inflammatory bowel disease: Immunomodulatory effect of retinoic acid. J. Interferon Cytokine Res. 2013, 33, 353. [CrossRef] [PubMed]

20. Scheerens, H.; Hessel, E.; deWaal-Malefyt, R.; Leach, M.W.; Rennick, D. Characterization of chemokines and chemokine receptors in two murine models of inflammatory bowel disease: IL-10-/- mice and Rag-2-/- mice reconstituted with CD4+CD45RBhigh T cells. Eur. J. Immunol. 2001, 31, 1465-1474. [CrossRef]

21. Varona, R.; Cadenas, V.; Flores, J.; Martinez, A.C.; Marquez, G. CCR6 has a non-redundant role in the development of inflammatory bowel disease. Eur. J. Immunol. 2003, 33, 2937-2946. [CrossRef] [PubMed]

22. Teramoto, K.; Miura, S.; Tsuzuki, Y.; Hokari, R.; Watanabe, C.; Inamura, T.; Ogawa, T.; Hosoe, N.; Nagata, H.; Ishii, H.; et al. Increased lymphocyte trafficking to colonic microvessels is dependent on MAdCAM-1 and C-C chemokine mLARC/CCL20 in DSS-Induced mice colitis. Clin. Exp. Immunol. 2005, 139, 421-428. [CrossRef] [PubMed]

23. Katchar, K.; Kelly, C.P.; Keates, S.; O’brien, M.J.; Keates, A.C. MIP-3alpha neutralizing monoclonal antibody protects against TNBS-induced colonic injury and inflammation in mice. Am. J. Physiol. Gastrointest. Liver Physiol. 2007, 292, G1263-G1271. [CrossRef] [PubMed]

24. Eijkelkamp, N.; Heijnen, C.J.; Lucas, A.; Premont, R.T.; Elsenbruch, S.; Schedlowski, M.; Kavelaars, A. G protein-coupled receptor kinase 6 controls chronicity and severity of dextran sodium sulphate-induced colitis in mice. Gut 2007, 56, 847-854. [CrossRef] [PubMed]

25. Blazquez, A.B.; Knight, A.K.; Getachew, H.; Bromberg, J.S.; Lira, S.A.; Mayer, L.; Berin, M.C. A functional role for CCR6 on pro-allergic T cells in the gastrointestinal tract. Gastroenterology 2010, 138, 275-284. [CrossRef] [PubMed] 
26. Atreya, R.; Neurath, M.F. Chemokines in inflammatory bowel diseases. Dig. Dis. 2010, 28, 386-394. [CrossRef] [PubMed]

27. Uchida, K.; Koike, Y.; Hashimoto, K.; Saigusa, S.; Inoue, M.; Otake, K.; Tanaka, K.; Matsushita, K.; Okita, Y.; Fujikawa, H.; et al. The increased expression of CCL20 and CCR6 in rectal mucosa correlated to severe inflammation in pediatric ulcerative colitis. Gastroenterol. Res. Pract. 2015. [CrossRef] [PubMed]

28. Pezoldt, J.; Huehn, J. Tissue specific induction of CCR6 and Nrp1 during early CD4+ T cell differentiation. Eur. J. Microbiol. Immunol. 2016, 6, 219-226. [CrossRef] [PubMed]

29. Yang, F.; Wang, D.; Li, Y.; Sang, L.; Zhu, J.; Wang, J.; Wei, B.; Lu, C.; Sun, X. Th1/Th2 balance and Th17/Treg -mediated immunity in relation to murine resistance to dextran sulfate-induced colitis. J. Immunol. Res. 2017. [CrossRef] [PubMed]

30. Lim, H.W.; Lee, J.; Hillsamer, P.; Kim, C.H. Human Th17 cells share major trafficking receptors with both polarized effector T cells and FOXP3+ regulatory T cells. J. Immunol. 2008, 180, 122-129. [CrossRef] [PubMed]

31. Wang, C.; Kang, S.G.; Lee, J.; Sun, Z.; Kim, C.H. The roles of CCR6 in migration of Th17 cells and regulation of effector T cell balance in the gut. Mucosal Immunol. 2009, 2, 173-183. [CrossRef] [PubMed]

32. Kleinschek, M.A.; Boniface, K.; Sadekova, S.; Grein, J.; Murphy, E.E.; Turner, S.P.; Raskin, L.; Desai, B.; Faubion, W.A.; de Waal Malefyt, R.; et al. Circulating and gut-resident human Th17 cells express CD161 and promote intestinal inflammation. J. Exp. Med. 2009, 206, 525-534. [CrossRef] [PubMed]

33. Ahern, P.P.; Schiering, C.; Buonocore, S.; McGeachy, M.J.; Cua, D.J.; Maloy, K.J.; Powrie, F. Interleukin-23 drives intestinal inflammation through direct activity on T cells. Immunity 2010, 33, 279-288. [CrossRef] [PubMed]

34. El-Bassat, H.; Ali, L.A.; El Yamany, S.; Al Shenawy, H.; Al Din, R.A.; Taha, A. Interleukin-23p 19 expression in patients with ulcerative colitis and its relation to disease severity. Adv. Dig. Med. 2016, 3, 88-94. [CrossRef]

35. Esplugues, E.; Huber, S.; Gagliani, N.; Hauser, A.E.; Town, T.; Wan, Y.Y.; O'Connor, W., Jr.; Rongvaux, A.; Van Rooijen, N.; Haberman, A.M.; et al. Control of Th17 cells occurs in the small intestine. Nature 2011, 475, 514-518. [CrossRef] [PubMed]

36. Zhang, W.; Ferguson, J.; Ng, S.M.; Hui, K.; Goh, G.; Lin, A.; Esplugues, E.; Flavell, R.A.; Abraham, C.; Zhao, H.; et al. Effector CD4+ T cell expression signatures and immune-mediated disease associated genes. PLoS ONE 2012, 7, e38510. [CrossRef] [PubMed]

37. Duhen, T.; Campbell, D.J. IL-1 $\beta$ promotes the differentiation of polyfunctional human CCR6+CXCR3+ Th1/17 cells that are specific for pathogenic and commensal microbes. J. Immunol. 2014, 193, 120-129. [CrossRef] [PubMed]

38. Huang, H. The Role of CD39 in Modulating Effector Immune Responses in Inflammatory Bowel Disease. Ph.D. Thesis, Harvard Medical School, Boston, MA, USA, 2015.

39. Longhi, M.S.; Vuerich, M.; Kalbasi, A.; Kenison, J.E.; Yeste, A.; Csizmadia, E.; Vaughn, B.; Feldbrugge, L.; Mitsuhashi, S.; Wegiel, B.; et al. Bilirubin suppresses Th17 immunity in colitis by upregulating CD39. JCI Insight 2017, 2, e92791. [CrossRef] [PubMed]

40. Hildner, K.; Punkenburg, E.; Abendroth, B.; Neurath, M.F. Immunopathogenesis of IBD: Batf as a key driver of disease activity. Dig. Dis. 2016, 34 (Suppl. S1), 40-47. [CrossRef] [PubMed]

41. Haas, J.D.; Gonzalez, F.H.; Schmitz, S.; Chennupati, V.; Fohse, L.; Kremmer, E.; Forster, R.; Prinz, I. CCR6 and NK1.1 distinguish between IL-17A and IFN- gamma-producing gammadelta effector T cells. Eur. J. Immunol. 2009, 39, 3488-3497. [CrossRef] [PubMed]

42. Do, J.; Visperas, A.; Dong, C.; Baldwin, W.M., III; Min, B. Generation of colitogenic Th17 CD4 T cells is enhanced by IL-17+ $\gamma \delta$ T cells. J. Immunol. 2011, 186, 4546-4550. [CrossRef] [PubMed]

43. Geremia, A.; Arancibia-Carcamo, C.V.; Fleming, M.P.; Rust, N.; Singh, B.; Mortensen, N.J.; Travis, S.P.; Powrie, F. IL-23 - responsive innate lymphoid cells are increased in inflammatory bowel disease. J. Exp. Med. 2011, 208, 1127-1133. [CrossRef] [PubMed]

44. Hepworth, M.R.; Fung, T.C.; Masur, S.H.; Kelsen, J.R.; McConnell, F.M.; Dubrot, J.; Withers, D.R.; Hugues, S.; Farrar, M.A.; Reith, W.; et al. Group 3 innate lymphoid cells mediate intestinal selection of commensal bacteria-specific CD4+ T cells. Science 2015, 348, 1031-1035. [CrossRef] [PubMed]

45. Kwon, J.H.; Keates, S.; Bassani, L.; Mayer, L.F.; Keates, A.C. Colonic epithelial cells are a major site of macrophage inflammatory protein 3 alpha (MIP-3alpha) production in normal colon and inflammatory bowel disease. Gut 2002, 51, 818-826. [CrossRef] [PubMed] 
46. Lee, H.J.; Choi, S.C.; Lee, M.H.; Oh, H.M.; Choi, E.Y.; Choi, E.J.; Yun, K.J.; Seo, G.S.; Kim, S.W.; Lee, J.G.; et al. Increased expression of MIP-3alpha/CCL20 in peripheral blood mononuclear cells from patients with ulcerative colitis and its down-regulation by sulfasalazine and glucocorticoid treatment. Inflamm. Bowel Dis. 2005, 11, 1070-1079. [CrossRef] [PubMed]

47. Puleston, J.; Cooper, M.; Murch, S.; Bid, K.; Makh, S.; Ashwood, P.; Bingham, A.H.; Green, H.; Moss, P.; Dhillon, A.; et al. A distinct subset of chemokines dominates the mucosal chemokine response in inflammatory bowel disease. Aliment. Pharmacol. Ther. 2005, 21, 109-120. [CrossRef] [PubMed]

48. Macho-Fernandez, E.; Koroleva, E.P.; Spencer, C.M.; Tighe, M.; Torrado, E.; Cooper, A.M.; Fu, Y.X.; Tumanov, A.V. Lymphotoxin beta receptor signalling limits mucosal damage through driving IL-23 production by epithelial cells. Mucosal Immunol. 2015, 8, 403-413. [CrossRef] [PubMed]

49. Marafini, I.; Monteleone, I.; Dinallo, V.; Di Fusco, D.; De Simone, V.; Laudisi, F.; Fantini, M.C.; Di Sabatino, A.; Pallone, F.; Monteleone, G. CCL20 is negatively regulated by TGF- $\beta 1$ in intestinal epithelial cells and reduced in Crohn's disease patients with a successful response to Mongersen, a smad7 antisense oligonucleotide. J. Crohns Colitis 2017, 11, 603-609. [CrossRef] [PubMed]

50. Lin, Y.L.; Ip, P.P.; Liao, F. CCR6 deficiency impairs IgA production and dysregulates antimicrobial peptide production, altering the intestinal flora. Front. Immunol. 2017, 8, 805. [CrossRef] [PubMed]

51. Lugering, A.; Floer, M.; Westphal, S.; Maaser, C.; Spahn, T.W.; Schmidt, M.A.; Domschke, W.; Williams, I.R.; Kucharzik, T. Absence of CCR6 inhibits CD4+ regulatory T cell development and M cell formation inside peyer's patches. Am. J. Pathol. 2005, 166, 1647-1654. [CrossRef]

52. Williams, I.R. CCR6 and CCL20 partners in intestinal immunity and lymphorganogenesis. Ann. N. Y. Acad. Sci. 2016. [CrossRef] [PubMed]

53. Westphal, S.; Lugering, A.; von Wedel, J.; von Eiff, C.; Maaser, C.; Spahn, T.; Heusipp, G.; Schmidt, M.A.; Herbst, H.; Williams, I.R.; et al. Resistance of chemokine receptor 6-deficient mice to Yersinia Enterocolitica infection: Evidence of defective M-cell formation in vivo. Am. J. Pathol. 2008, 172, 671-680. [CrossRef] [PubMed]

54. Hashimoto, K.; Saigusa, S.; Araki, T.; Tanaka, K.; Okita, Y.; Fujikawa, H.; Kawamura, M.; Okugawa, Y.; Toiyama, Y.; Inoue, Y.; et al. Correlation of CCL20 expression in rectal mucosa with the development of ulcerative colitis-associated neoplasia. Oncol. Lett. 2013, 6, 1271-1276. [CrossRef] [PubMed]

55. Brand, S.; Olszak, T.; Beigel, F.; Diebold, J.; Otte, J.M.; Eichhorst, S.T.; Goke, B.; Dambacher, J. Cell differentiation dependent expressed CCR6 mediates ERK-1/2, SAPK/JNK and Akt signalling resulting in proliferation and migration of colorectal cancer cells. J. Cell Biochem. 2006, 97, 709-723. [CrossRef] [PubMed]

56. Frick, V.O.; Rubie, C.; Kolsch, K.; Wagner, M.; Ghadjar, P.; Graeber, S.; Glanemann, M. CCR6/CCL20 chemokine expression profile in distinct colorectal malignancies. Scand. J. Immunol. 2013, 78, 298-305. [CrossRef] [PubMed]

57. Nandi, B.; Shapiro, M.; Samur, M.K.; Pai, C.; Frank, N.Y.; Yoon, C.; Prabhala, R.H.; Munshi, N.C.; Gold, J.S. Stromal CCR6 drives tumor growth in a murine transplantable colon cancer through recruitment of tumor-promoting macrophages. Oncoimmunology 2016, 5, e1189052. [CrossRef] [PubMed]

58. Monteiro, P.; Gosselin, A.; Wacleche, V.S.; El-Far, M.; Said, E.A.; Kared, H.; Grandvaux, N.; Boulassel, M.R.; Routy, J.P.; Ancuta, P. Memory CCR6+CD4+ T cells are preferential targets for productive HIV type 1 infection regardless of their expression of integrin $\beta 7$. J. Immunol. 2011, 186, 4618-4630. [CrossRef] [PubMed]

59. Wunderlich, C.M.; Ackermann, P.J.; Ostermann, A.L.; Adams-Quack, P.; Vogt, C.; Tran, M.L.; Nikolaiev, A.; Waisman, A.; Garbers, C.; Theurich, S.; et al. Obesity exacerbates colitis-associated cancer via IL-6-regulated macrophage polarisation and CCL-20/CCR-6-mediated lymphocyte recruitment. Nat. Commun. 2018, 9, 1646. [CrossRef] [PubMed]

60. Kitamura, K.; Farber, J.M.; Kelsall, B.L. CCR6 marks regulatory T cells as a colon-tropic, IL-10-producing phenotype. J. Immunol. 2010, 185, 3295-3304. [CrossRef] [PubMed]

61. Rivino, L.; Gruarin, P.; Haringer, B.; Steinfelder, S.; Lozza, L.; Steckel, B.; Weick, A.; Sugliano, E.; Jarrossay, D.; Kuhl, A.A.; et al. CCR6 is expressed on an IL-10-producing, autoreactive memory T cell population with context-dependent regulatory function. J. Exp. Med. 2010, 207, 565-577. [CrossRef] [PubMed]

62. Kryczek, I.; Wu, K.; Zhao, E.; Wei, S.; Vatan, L.; Szeliga, W.; Huang, E.; Greenson, J.; Chang, A.; Rolinski, J.; et al. IL-17+ regulatory T cells in the microenvironments of chronic inflammation and cancer. J. Immunol. 2011, 186, 4388-4395. [CrossRef] [PubMed] 
63. Kryczek, I.; Wang, L.; Wu, K.; Li, W.; Zhao, E.; Cui, T.; Wei, S.; Liu, Y.; Wang, Y.; Vatan, L.; et al. Inflammatory regulatory $\mathrm{T}$ cells in the microenvironments of ulcerative colitis and colon carcinoma. Oncoimmunology 2016, 5, e1105430. [CrossRef] [PubMed]

64. Kulkarni, N.; Meitei, H.T.; Sonar, S.A.; Sharma, P.K.; Mujeeb, V.R.; Srivastava, S.; Boppana, R.; Lal, G. CCR6 signaling inhibits suppressor function of induced-Treg during gut inflammation. J. Autoimmun. 2018, 88, 121-130. [CrossRef] [PubMed]

65. Godefroy, E.; Alameddine, J.; Montassier, E.; Mathé, J.; Desfrançois-Noël, J.; Marec, N.; Bossard, C.; Jarry, A.; Bridonneau, C.; Le Roy, A.; et al. Expression of CCR6 and CXCR6 by gut-derived CD4+/CD8alpha+ T-regulatory cells which are decreased in blood samples from patients with inflammatory bowel diseases. Gastroenterology 2018. [CrossRef] [PubMed]

66. Yamazaki, T.; Yang, X.O.; Chung, Y.; Fukunaga, A.; Nurieva, R.; Pappu, B.; Martin-Orozco, N.; Kang, H.S.; Ma, L.; Panopoulos, A.D.; et al. CCR6 regulates the migration of inflammatory and regulatory T cells. J. Immunol. 2008, 181, 8391-8401. [CrossRef] [PubMed]

67. Lochner, M.; Peduto, L.; Cherrier, M.; Sawa, S.; Langa, F.; Varona, R.; Riethmacher, D.; Si-Tahar, M.; Di Santo, J.P.; Eberl, G. In vivo equilibrium of pro-inflammatory IL-17+ and regulatory IL-10+ Foxp3+ ROR $\gamma \mathrm{t}+$ T cells. J. Exp. Med. 2008, 205, 1381-1393. [CrossRef] [PubMed]

68. Chaudhry, A.; Rudra, D.; Treuting, P.; Samstein, R.M.; Liang, Y.; Kas, A.; Rudensky, A.Y. CD4+ regulatory T cells control Th17 responses in a Stat3-dependent manner. Science 2009, 326, 986-991. [CrossRef] [PubMed]

69. Kaser, A.; Ludwiczek, T.; Holzmann, S.; Moschen, A.R.; Weiss, G.; Enrich, B.; Graziadei, I.; Dunzendorfer, S.; Wiedermann, C.J.; Murzl, E.; et al. Increased expression of CCL20 in human inflammatory bowel disease. J. Clin. Immunol. 2004, 24, 74-85. [CrossRef] [PubMed]

70. Dieu-Nosjean, M.; Massacrier, C.; Vanbervliet, B.; Fridman, W.; Caux, C. IL-10 induces CCR6 expression during Langerhans cell development while IL-4 and IFN- $\gamma$ suppress it. J. Immunol. 2001, 167, 5594-5602. [CrossRef] [PubMed]

71. Salazar-Gonzalez, R.M.; Niess, J.H.; Zammit, D.J.; Ravindran, R.; Srinivasan, A.; Maxwell, J.R.; Stoklasek, T.; Yadav, R.; Williams, I.R.; Gu, X.; et al. CCR6-mediated dendritic cell activation of pathogen-specific $\mathrm{T}$ cells in Peyer's patches. Immunity 2006, 24, 623-632. [CrossRef] [PubMed]

72. Watanabe, S.; Yamakawa, M.; Hiroaki, T.; Kawata, S.; Kimura, O. Correlation of dendritic cell infiltration with active crypt inflammation in ulcerative colitis. Clin. Immunol. 2007, 122, 288-297. [CrossRef] [PubMed]

73. Siddiqui, K.R.R.; Laffont, S.; Powrie, F. E-Cadherin marks a subset of inflammatory dendritic cells that promote T cell mediated-colitis. Immunity 2010, 32, 557-567. [CrossRef] [PubMed]

74. Hornung, M.; Werner, J.M.; Farkas, S.; Schlitt, H.J.; Geissler, E.K. Migration and chemokine receptor pattern of colitis-preventing DX5+NKT cells. Int. J. Colorectal Dis. 2011, 26, 1423-1433. [CrossRef] [PubMed] 